\title{
Impact of wean to standing reflex interval on litter size of sows (Short Communication)
}

\author{
Petr Humpolicek ${ }^{1,2}$, Zdenek Tvrdon ${ }^{3}$ and Jiri Jaros ${ }^{2}$ \\ 'Faculty of Technology, Tomas Bata University in Zlín, Zlín, Czech Republic, ${ }^{2}$ Centre of Polymer Systems, Polymer \\ Centre, Tomas Bata University in Zlin, Zlin , Czech Republic, ${ }^{3}$ AVOS, Co., Czech Republic
}

\begin{abstract}
Sow reproduction influences farm economy and can be considered as key factor of pig production efficiency. The aim of this study is to evaluate the effect of wean to standing reflex interval on the total number of piglets born and correlated number of piglets born alive and number of piglets weaned. Study was performed on crossbreed of Large White and Landrace sows originated from a commercial farm thus our results describe the real effect under commercial conditions. The results indicate that wean to standing reflex interval influence the litter size traits negatively if this interval is longer than $108 \mathrm{~h}$. Highest differences was detected between 84 and $108 \mathrm{~h}$ of wean to standing reflex interval where decreasing about 2.8 total number of piglets weaned $(P \leq 0.01)$ was found. Mutually only small effect of number of inseminations was detected.
\end{abstract}

Keywords: standing reflex, selection, litter size, sow

\section{Introduction}

The economically most important trait in pig production is litter size. Most important factors affecting litter size are as follows: Time of returning to oestrus after weaning. It is recognized that sows returning to oestrus 6 or more days after weaning have lower fertility than those returning 4 or 5 days after weaning. Parity numbers influence the litter size probably because partly different genes control reproductive traits in successive parities (Noguera et al. 2002). This indicates that different parities should be treated as different traits. Another factor concerning litter size is weaning to oestrus interval (Patterson et al. 2008), in our study weaning to standing reflex interval (W-SR). Also age at puberty (Sterning et al. 1998, Tummaruk et al. 2007), average daily gain (Tummaruk et al. 2009) number and type of insemination (Casas et al. 2010) year and season (Chen et al. 2010) affect the reproduction traits. Because our study is based on the data from commercial herd the effect of crossbreeding plays crucial role (Canario et al. 2006). Crossbreeding effect can be evaluated using information about the sow's parents and effect of board. Following this, it might be desirable to consider the period from weaning to standing reflex as easy observable and recognizable trait for selection of sows after first parturition. In present study the impact of weaning to standing reflex interval in combination with number of inseminations on total number of piglets born, number of piglets born alive and number of piglets weaned of sows originated from commercial herd were studied. 


\section{Material and methods}

\section{Experimental procedure}

All sows were crossbreeds of Large White and Landrace originated from a commercial farm and they were bred in the same herd during the study. Sows were checked twice a day for the standing reflex by the back pressure test in presence of an adult boar. All sows included in the study were inseminated using $80 \mathrm{ml}$. The inseminations (always in the presence of mature boar) were performed twice a day either 12 or $24 \mathrm{~h}$ after standing reflex detection. All sows were checked for pregnancy by sonography test on the 30th day after insemination. The litter size was specified by the total number of piglets born (TNB; defined as the number of all fully formed foetuses expelled at farrowing, dead or alive), number of piglets born alive (NBA; defined as the number of piglets alive immediately after birth) and number of piglets weaned (NW; defined as the number of piglets available on the 28th day of the piglets' age).

\section{Statistical analyses}

Total number of 29644 litters of 7395 sows were used in computation. The information about the wean to standing reflex interval (W-SR), number of inseminations and standing reflexes to first insemination interval were known in case of 1226 litters. The present study was conducted in the period between January 2008 and June 2010. The computation was performed using mixed linear model procedure REML in SAS for Windows 9.1.2. (SAS Institute Inc., Cary, NC, USA). The statistical model included the following fixed factors: wean to standing reflex interval (W-SR) in interaction with number of inseminations ( $\mathrm{NI})$, year of birth $(\mathrm{YB})$, interaction between year and month of litter $(\mathrm{YML})$, standing reflex to first insemination interval (SR-II), parity number (PN), age at puberty (AP) and average daily gain (ADG). The random effect of sires, dams and boars used for mating was taken into account as the source of genetic variation. The analyses of litter size traits were performed within second to sixth parity. Statistical model:

$$
y_{i j k l m n o p r s}=\mu+W-S R \times N I_{i}+Y B_{j}+Y M L_{k}+S R-I I_{l}+P N_{m}+A P_{n}+A D G_{o}+S i r e_{p}+\text { Dam }_{r}+\text { Boar }_{s}+e_{i j k l m n o p r s}
$$

\section{Results and discussion}

Every study concerning litter size must consider that a complex of physiological, genetic and environmental factors and their interactions influence this trait. This complexity caused problematic breeding and even studying. Most important factors were mentioned in the introduction and all of them were incorporated into computation except for the type of mating since all sows were inseminated in our experiment.

The results presented in Table 1 show that litter size is well-proportioned without statistically significant differences when W-SR is between 84 and $108 \mathrm{~h}$. Number of inseminations does not affect litter size either. It seems possible to eliminate insemination four times since three inseminations seem to be sufficient. These results correspond with the known fact that by pigs the litter size is conditioned by optimal fertility which is obtained by insemination in period of $24 \mathrm{~h}$ before ovulation (Soede et al. 1995). However, when the onset of standing reflex does not occur within $108 \mathrm{~h}$, the differences are not negligible. Above 
this period of time the litter size traits prove to be significantly lower. Although statistically significant difference between three and four inseminations in case of W-SR within $108 \mathrm{~h}$ was observed, its incidence was restricted only to this specific W-SR interval. Holm et al. 2005 in their study show that genetic variance for interval from weaning to first service, which correspond to W-SR, after first litter exist and selection for this trait is therefore possible. Nevertheless, the potential selection for W-SR is being complicated by low heritability found by Sterning et al. 1998 which found the heritability of weaning to oestrus interval which corresponds to $S R$ is 0.24 . The low heritability for the weaning to first service interval was found by Rydhmer (2000) which is furthermore decreasing for later parities (Hanenberg et al. 2001). The selection for W-SR can be potentially substitute by selection for age at first service since genetic correlation exist between these traits (Hanenberg et al. 2001).

In conclusion, the key factor for successful breeding is the number of piglets weaned or, more generally, the reproduction ability. In present study the impact of weaning to standing reflex interval and number of inseminations on litter size traits is computed. Presented results indicate that this interval influence the litter size traits negatively if longer than $108 \mathrm{~h}$. Consequently the sows with longer weaning to standing reflex interval should not be preferred for another breeding. This can be useful since the ability to identify young females with superior reproduction would have a large economic impact on commercial swine production.

Table 1

Impact of weaning to standing reflex interval on litter size.

\begin{tabular}{lccc}
\hline W-SR/NI & TNB & NBA & NW \\
\hline $84 / 3$ & $13.0408 \pm 0.4799^{\text {Aa }}$ & $10.8331 \pm 0.4144^{\mathrm{a}}$ & $9.9866 \pm 0.2974$ \\
$84 / 4$ & $12.7052 \pm 0.4445^{\mathrm{c}}$ & $10.8754 \pm 0.3823^{\mathrm{c}}$ & $10.1961 \pm 0.2790^{\mathrm{A}}$ \\
$96 / 3$ & $12.5522 \pm 0.7919$ & $11.3222 \pm 0.6934^{\mathrm{c}}$ & $10.3368 \pm 0.4700^{\mathrm{a}}$ \\
$96 / 4$ & $12.0196 \pm 0.6808^{*}$ & $10.5739 \pm 0.5947^{\mathrm{a}}$ & $10.0948 \pm 0.4096^{\mathrm{a}}$ \\
$108 / 3$ & $13.5267 \pm 0.6855^{\text {Ac }}$ & $11.4916 \pm 0.5980^{\text {Ac }}$ & $9.9563 \pm 0.4117^{\mathrm{a}}$ \\
$108 / 4$ & $10.9627 \pm 0.8789^{\mathrm{Bd}}$ & $9.4393 \pm 0.7700^{\mathrm{d}}$ & $8.8748 \pm 0.5178^{\mathrm{Bb}}$ \\
$120 / 3$ & $12.1989 \pm 0.7363^{\text {c** }}$ & $10.8721 \pm 1.5227^{*}$ & $10.8330 \pm 1.0092^{* *}$ \\
$132 / 3$ & $11.8995 \pm 0.8776^{*}$ & $10.2390 \pm 0.7691^{*}$ & $9.9765 \pm 0.5188^{*}$ \\
$132 / 4$ & $12.8246 \pm 2.3930$ & $10.6363 \pm 2.1150$ & $10.2382 \pm 1.3762$ \\
$156 / 3$ & $9.3940 \pm 1.9145^{\text {bd }}$ & $7.0384 \pm 1.6877^{\mathrm{Bbd}}$ & $7.0035 \pm 1.1128$ \\
$168 / 3$ & $10.8637 \pm 2.9087$ & $10.8271 \pm 1.8665$ & $9.9805 \pm 3.2804$ \\
\hline
\end{tabular}

W-SR/NI: Wean to standing reflex interval and number of inseminations. First numbers are hours from wean to standing reflex and second numbers are number of inseminations, TNB: total number of piglets born, NBA: number of piglets born alive, NW: number of piglets weaned. ${ }^{A, B} P \leq 0.01, \quad,{ }^{a}, b ; c, d P \leq 0.05,{ }^{*}{ }^{* * *} P \leq 0.1$

\section{Acknowledgement}

This article was created with support of Operational Program Research and Development for Innovations co-funded by the European Regional Development Fund (ERDF) and national budget of Czech Republic, within the framework of project Centre of Polymer Systems (reg. number: CZ.1.05/2.1.00/03.0111). The work was supported by the Research project of Ministry of Education, Youth and Sports of the Czech Republic (MSM 7088352101). 


\section{References}

Canario L, Cantoni E, Le Bihan E, Caritez JC, Billon Y, Bidanel JP, Foulley JL (2006) Between-breed variability of stillbirth and its relationship with sow and piglet characteristics. J Anim Sci 84, 3185-3196

Casas I, Sancho S, Briz M, Pinart E, Bussalleu E, Yeste M, Bonet S (2010) Fertility after post-cervical artificial insemination with cryopreserved sperm from boar ejaculates of good and poor freezability. Anim Reprod Sci 118, 69-76

Chen CY, Misztal I, Tsuruta S, Herring WO, Holl J, Culbertson M (2010) Genetic analyses of stillbirth in relation to litter size using random regression models. J Anim Sci 88, 3800-3808

Hanenberg EHAT, Knoll EF, Merks JWM (2001) Estimates of genetic parameters for reproduction traits at different parities in Dutch Landrace pigs. Livest Prod Sci 69, 179-186

Holm B, Bakken M, Vangen O, Rekaya R (2005) Genetic analysis of age at first service, return rate, litter size, and weaning-to-first service interval of gilts and sows. J Anim Sci 83, 41-48

Noguera JL, Varona L, Babot D, Estany J (2002) Multivariate analysis of litter size for multiple parities with production traits in pigs: I. Bayesian variance component estimation. J Anim Sci 80, 2540-2547

Patterson J, Wellen A, Hahn M, Pasternak A, Lowe J, DeHaas S, Kraus D, Williams N, Foxcroft G (2008) Responses to delayed estrus after weaning in sows using oral progestagen treatment. J Anim Sci 86, 1996-2004

Rydhmer L (2000) Genetics of sow reproduction, including puberty, oestrus, pregnancy, farrowing and lactation. Livest Prod Sci 66, 1-12

Soede NM, Wetzels CCH, Zondag W, de Koning MAl, Kemp B (1995) Effects of time of insemination relative to ovulation, as determined by ultrasonography, on fertilization rate and accessory sperm count in sows. J Reprod Fertil 104, 99-106

Sterning M, Rydhmer L, Eliasson-Selling $L$ (1998) Relationships between age at puberty and interval from weaning to estrus and between estrus signs at puberty and after the first weaning in pigs. J Anim Sci 76, 353-359

Tummaruk P, Tantasuparuk W, Techakumphu M, Kunavongkrit A (2007) Age, body weight and backfat thickness at first observed oestrus in crossbred Landrace $\times$ Yorkshire gilts, seasonal variations and their influence on their subsequent reproductive performance. Anim Reprod Sci 99, 167-181

Tummaruk P, Tantasuparuk W, Techakumphu M, Kunavongkrit A (2009) The association between growth rate, body weight, backfat thickness and age at first observed oestrus in crossbred Landrace $\times$ Yorkshire gilts. Anim Reprod Sci 110, 108-122

Received, accepted 27 April 2011, 22 September 2011.

Corresponding author:

Petr Humpolicek

email: humpolicek@ft.utb.cz

Tomas Bata University in Zlín, T.G.M Sq 5555, 76001, Zlín, Czech Republic 